Ferrata Storti Foundation

\title{
ASLAN003, a potent dihydroorotate dehydrogenase inhibitor for differentiation of acute myeloid leukemia
}

Haematologica 2020

Volume 105(9):2286-2297

\section{Correspondence:}

WEE-JOO CHNG

mdccwi@nus.edu.sg

Received: June 22, 2019.

Accepted: November 5, 2019.

Pre-published: November 7, 2019.

doi:10.3324/haematol.2019.230482

(C)2020 Ferrata Storti Foundation

Material published in Haematologica is covered by copyright. All rights are reserved to the Ferrata Storti Foundation. Use of published material is allowed under the following terms and conditions:

https://creativecommons.org/licenses/by-nc/4.0/legalcode. Copies of published material are allowed for personal or internal use. Sharing published material for non-commercial purposes is subject to the following conditions:

https://creativecommons.org/licenses/by-nc/4.0/legalcode, sect. 3. Reproducing and sharing published material for commercial purposes is not allowed without permission in writing from the publisher.

\author{
Jianbiao Zhou,,${ }^{1,2}$ Jessie Yiying Quah, ${ }^{1 *}$ Yvonne $\mathrm{Ng},{ }^{1 \star}$ Jing-Yuan Chooi, ${ }^{2 \star}$ \\ Sabrina Hui-Min Toh, ${ }^{1 *}$ Baohong Lin, ${ }^{3}$ Tuan Zea Tan, ${ }^{1}$ Hiroki Hosoi, ${ }^{1}$ \\ Motomi Osato, ${ }^{1,4}$ Qihui Seet, ${ }^{5}$ A.G. Lisa Ooi, ${ }^{5}$ Bertil Lindmark, ${ }^{5}$ Mark McHale ${ }^{5}$ \\ and Wee-Joo Chng C.,2, $^{1,3}$
}

${ }^{1}$ Cancer Science Institute of Singapore, National University of Singapore; ${ }^{2}$ Department of Medicine, Yong Loo Lin School of Medicine, National University of Singapore; ${ }^{3}$ Department of Hematology-Oncology, National University Cancer Institute, NUHS; ${ }^{4}$ Department of Pediatrics, National University of Singapore, Yong Loo Lin School of Medicine and ${ }^{5}$ ASLAN Pharmaceuticals, Singapore

${ }^{*} \mathrm{YYQ}, \mathrm{YN}, \mathrm{J}-\mathrm{YC}$ and SH-MT contributed equally to this work.

\section{ABSTRACT}

$\mathrm{D}$ ifferentiation therapies achieve remarkable success in acute promyelocytic leukemia, a subtype of acute myeloid leukemia (AML). However, excluding acute promyelocytic leukemia, clinical benefits of differentiation therapies in AML are negligible except for those targeting mutant isocitrate dehydrogenase $1 / 2$. Dihydroorotate dehydrogenase catalyzes the fourth step of the de novo pyrimidine synthesis pathway. ASLAN003 is a highly potent dihydroorotate dehydrogenase inhibitor that induces differentiation, as well as reducing cell proliferation and viability, of AML cell lines and primary AML blasts including chemoresistant cells. Apoptotic pathways are triggered by ASLAN003, and this drug also significantly inhibits protein synthesis and activates AP-1 transcription, contributing to its capacity to promote differentiation. Finally, ASLAN003 substantially reduces leukemic burden and prolongs survival in AML xenograft mice and AML patient-derived xenograft models. Notably, the drug has no evident effect on normal hematopoietic cells and exhibits excellent safety profiles in mice, even after a prolonged period of administration. Our results, therefore, suggest that ASLAN003 is an agent targeting dihydroorotate dehydrogenase with potential for use in the treatment of AML. ASLAN003 is currently being evaluated in a phase IIa clinical trial in patients with AML.

\section{Introduction}

Acute myeloid leukemia (AML) cells originate from hematopoietic stem cells, but fail to differentiate into functional mature cells; instead, they are arrested at an early stage of differentiation..$^{1-4}$ AML-M3 (according to the French-American-British classification), acute promyelocytic leukemia, is a unique subtype with a specific $\mathrm{t}(15 ; 17)$ chromosomal translocation, resulting in the PML-RARA fusion gene. ${ }^{5}$ The introduction of all-trans retinoic acid, a vitamin A metabolite, and subsequently arsenic trioxide, transformed the clinical management of acute promyelocytic leukemia, turning a highly fatal disease into a definitively curable one that can be treated without the need for toxic chemotherapy.,

In contrast to their excellent effectiveness in acute promyelocytic leukemia, differentiation therapies have not been as effective in the other types of AML despite decades of intensive laboratory research and numerous clinical trials. The one exception to date is treatment targeting AML with mutated isocitrate dehydrogenase (IDH) 1 or 2.,9 Enasidenib, a selective, non-competitive inhibitor of IDH2, induces differentiation of AML cells through reducing the oncometabolite 2hydroxyglutarate in mutated IDH2. ${ }^{10}$ Ivosidenib, an IDH1 inhibitor, also induces differentiation through a similar mechanism in mutated IDH1. The approval of 
enasidenib and ivosidenib for relapsed/refractory AML with mutated IDH2 and mutated IDH1, respectively, by the USA Food and Drug Administration renewed enthusiasm for differentiation therapy.

Pyrimidines and pyrimidine derivatives are the building blocks of both deoxyribonucleic acid (DNA) and ribonucleic acid (RNA), and protein glycosylation, which are the essential cellular components. ${ }^{11}$ Dihydroorotate dehydrogenase (DHODH) catalyzes the fourth enzymatic step in de novo pyrimidine biosynthesis, converting the ubiquinone-mediated oxidation of dihydroorotate to orotate. ${ }^{12,13} \mathrm{DHODH}$ has been a therapeutic target for malaria, rheumatoid arthritis, and multiple sclerosis. ${ }^{14-16}$ Recently, an elegant study revealed an unexpected role of DHODH in the differentiation of AML blast cells. ${ }^{17}$ The DHODH inhibitor used in that study, brequinar, was originally discovered by $\mathrm{Du}$ Pont in $1985 .{ }^{17,18}$ However, clinical trials of brequinar in solid tumors demonstrated myelosuppression with predominant thrombocytopenia, which limit its potential use in AML. ${ }^{16,19}$

ASLAN003 (LAS186323) is a novel, bioavailable and potent small molecule DHODH inhibitor. The drug was discovered by Almirall, S.A. and global rights to the compound were granted to ASLAN Pharmaceuticals Singapore in 2012, which re-named it as ASLAN003. ASLAN003 is a potent inhibitor of human DHODH enzyme activity, with a half maximal inhibitory concentration $\left(\mathrm{IC}_{50}\right)$ of $35 \mathrm{nM}$, and high plasma protein binding (>99\%). In phase I single and multiple ascending dose clinical trials, ASLAN003 has been shown to be tolerated by healthy volunteers. In this study, we set out to investigate the effects of ASLAN003 on AML cell function in vitro and in vivo, as well as to elucidate the molecular mechanism of $\mathrm{DHODH}$ inhibition of AML cell differentiation.

\section{Methods}

\section{Cell lines and primary acute myeloid leukemia cells, drugs and chemicals}

Details on the cell lines and primary bone marrow (BM) cell culture, drugs and chemicals are provided in the Online Supplementary Methods.

\section{Cell viability assays, western blot analysis, polymerase chain reaction, and FACS analysis}

Experiments were conducted as previously described. ${ }^{20,21}$ Details of the cell viability assays, western blot analysis, realtime quantitative reverse transcriptase polymerase chain reaction (qRT-PCR), and FACS analysis of myeloid cell surface antigens are available in the Online Supplementary Methods. The primer sequences are provided in Online Supplementary Table S1.

\section{Wright-Giemsa staining and nitro blue tetrazolium assay}

After exposure to ASLAN003 or dimethylsulfoxide (DMSO) for 96 h, AML cells $\left(1 \times 10^{\circ}\right)$ were harvested and distributed equally for Wright-Giemsa staining and nitro blue tetrazolium (NBT) reduction assay (details in the Online Supplementary Methods).

\section{Assessment of mitochondrial membrane potential}

The mitochondrial membrane potential was determined using a JC-10 Assay Kit (Sigma, MAK160). Details are provided in the Online Supplementary Methods.

\section{RNA sequencing and data analysis}

The experiments and subsequent analysis of KG-1 and MOLM14 cells treated with ASLAN003 or DMSO were performed as detailed in the Online Supplementary Methods.

\section{Protein synthesis assays}

Click-iT assays were performed using an O-propargylpuromycin (OPP) Alexa Fluor ${ }^{\circledR} 88$ Protein Synthesis Assay Kit from ThermoFisher (C10456) according to the manufacturer's recommendation. MOLM-14 and KG-1 cells were exposed to ASLAN003 $1 \mu \mathrm{M}$ or $2 \mu \mathrm{M}$ for $1 \mathrm{~h}$ before OPP $20 \mathrm{mM}$ was added for $1 \mathrm{~h}$. DMSO was used as a control. Cells were washed in icecold phosphate-buffered saline and then fixed and permeabilized prior to FACS analysis using a LSRII flow cytometer (BD Biosciences).

\section{In vivo efficacy of ASLAN003}

The in vivo efficacy of ASLAN003 was tested in a human AML cell line xenograft model and in human AML patient-derived xenograft (PDX) models.

For the human AML cell line xenograft model, we used female NOD.Cg-Prkdcid Il2 $\mathrm{rg}^{\mathrm{tm} / W_{i} /} / \mathrm{Sz}$ J, NGS mice (4-6 weeks old), purchased from The Jackson Laboratory (Bar Harbor, ME, USA) through InVivos (Singapore). The animals were maintained in specific pathogen-free conditions. Exponentially growing THP-1 and MOLM-14 cells $\left(3 \times 10^{6}\right.$ each) were injected into mice via the tail vein. From the second day of inoculation of AML cells, the mice were administered either vehicle, as a control, or ASLAN003 50 $\mathrm{mg} / \mathrm{kg}$ by oral gavage once daily in a $200 \mu \mathrm{L}$ volume.

For the human AML PDX models, the AML-14 PDX line was established from a patient with AML-M4 with a normal karyotype, while the AML-23 PDX line was established from a patient diagnosed with chronic myeloid leukemia in accelerated phase.

The protocols were reviewed and approved by the Institutional Animal Care and Use Committee in compliance with guidelines on the care and use of animals for scientific purpose. More details are provided in the Online Supplementary Methods.

\section{Statistical analysis}

A Student $t$-test (two-tailed paired) was used to examine the statistical difference for in vitro cell line experiments, and $P$ values $<0.05$ were considered to be statistically significant. Data are presented as mean \pm standard deviation (SD). Kaplan-Meier analyses were conducted using GraphPad Prism ${ }^{\circledR}$ version 7 (GraphPad Software; La Jolla, CA, USA) and statistical significance was calculated by the log-rank test $(P<0.05)$.

\section{Data availability}

RNA-sequencing data for MOLM-14 and KG-1 cells have been deposited in the Gene Expression Omnibus with accession number GSE128950.

\section{Results}

ASLAN003 inhibits cell proliferation and induces cell differentiation of acute myeloid leukemia cell lines

ASLAN003 was found to inhibit leukemic cell proliferation of THP-1, MOLM-14 and KG-1 with $\mathrm{IC}_{50}$ values of $152 \mathrm{nM}, 582 \mathrm{nM}$, and $382 \mathrm{nM}$, respectively (Figure 1A). It is worth noting that cell viability was maintained at $~ 50 \%$ at ASLAN003 $1 \mu \mathrm{M}$ and higher (Figure 1A). This indicates that the mode of action of ASLAN003 differs from that of cytotoxic drugs, which cause increased cell death with higher doses. We also examined the selectivity of 
A

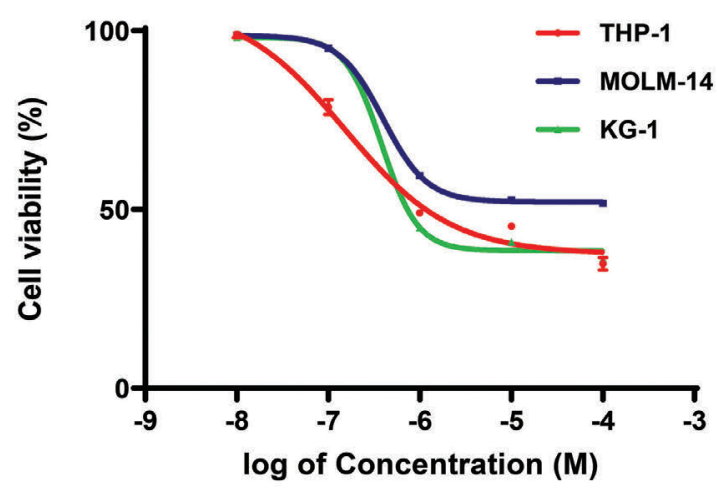

B
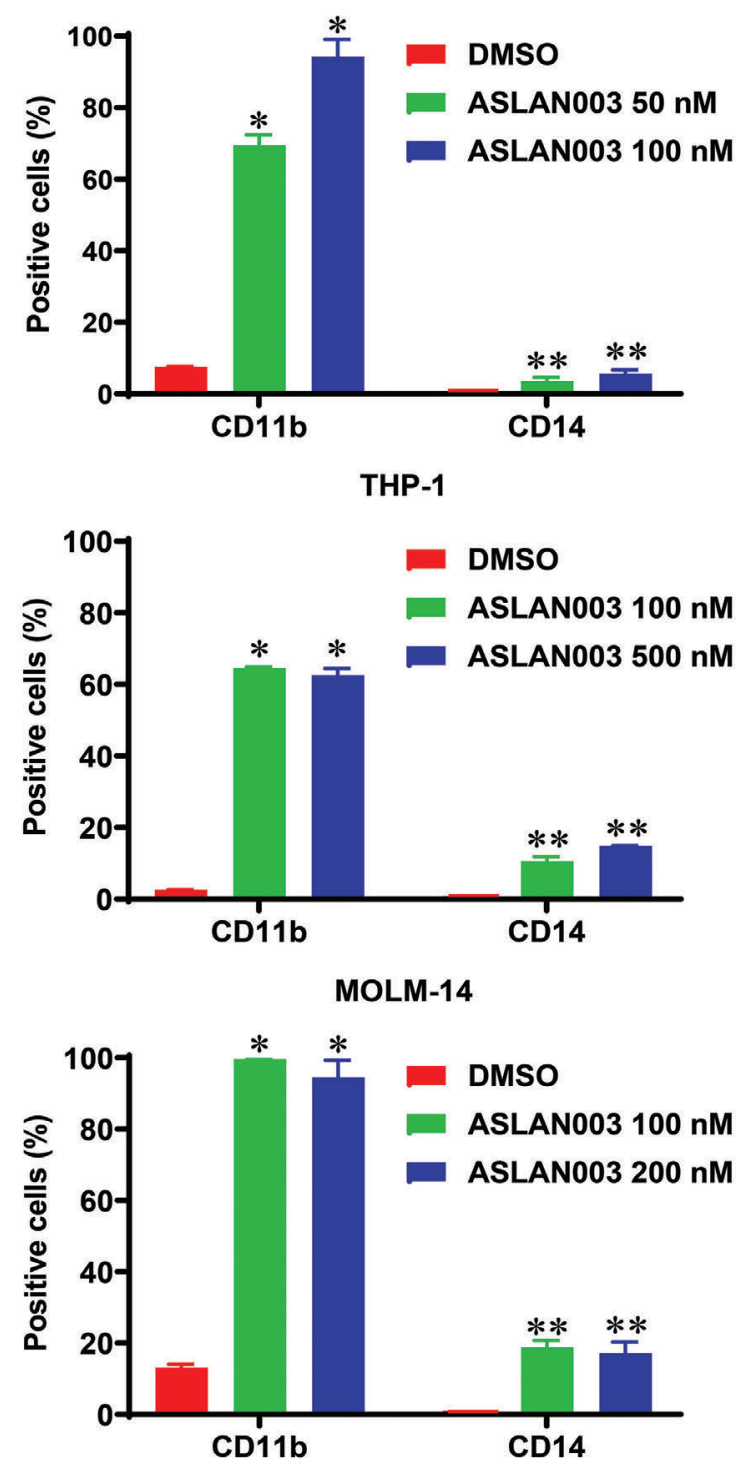

KG-1
C

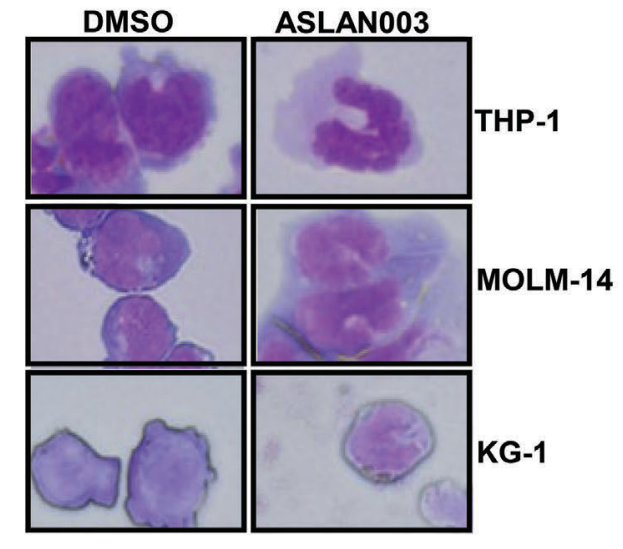

D

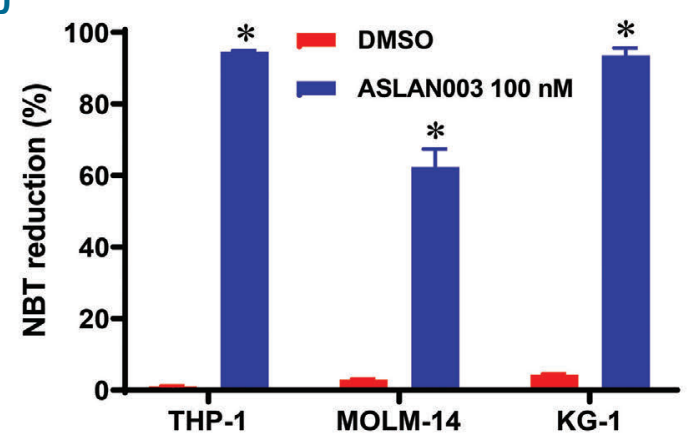

DMSO

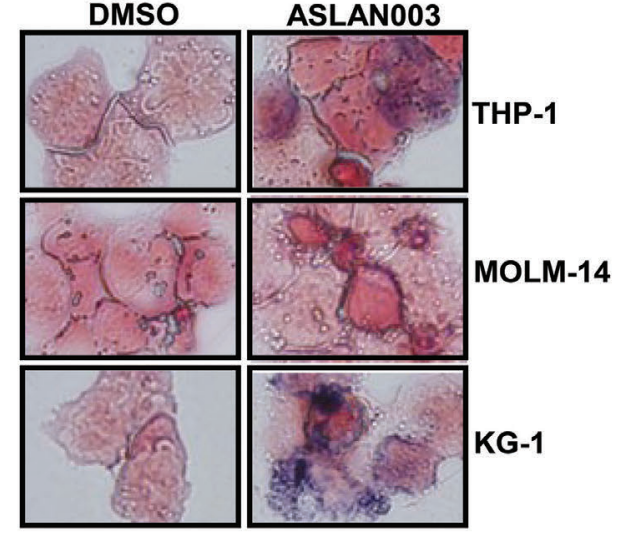

E

DMSO

- ASLAN003

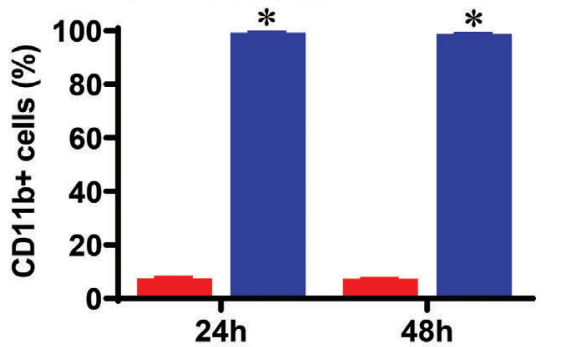

THP-1

Figure 1. Effects of ASLAN003 on cell viability and differentiation in human acute myeloid leukemia cell lines. (A) Dose-response curves of ASLANOO3 treatment for $48 \mathrm{~h}$ on cell viability of the acute myeloid leukemia (AML) cell lines THP-1, MOLM-14, and KG-1. The percentage of cell viability relative to that of dimethylsulfoxide (DMSO)-treated cells is shown. Data represent three independent replicates [mean \pm standard deviation (SD)]. (B) FACS analysis of myeloid differentiation cell surface antigens CD11b and CD14 on ASLAN003-treated and DMSO-treated AML cell lines. The treatment time was $96 \mathrm{~h}$. Data represent the mean \pm SD of three replicates. $* * P<0.01 ; * P<0.05$. (C) Representative images of Wright-Giemsa staining for morphological examination of AML cell lines treated with $100 \mathrm{nM}$ ASLAN003 or DMSO for $96 \mathrm{~h}$. The images were taken under an Olympus IX71 light microscope (Japan) with original magnification $x 400$ (objective lenses $x 40$ ). (D) Nitro blue tetrazolium (NBT) reduction assays for AML cells treated with $100 \mathrm{nM}$ ASLAN003 or DMSO for $96 \mathrm{~h}$. Cells positive for NBT-reducing activity, containing precipitated formazan particles, were counted. The bar graph shows the mean percentage of $\mathrm{NBT}^{+}$cells in ten random $10 \times$ (objective lenses) fields \pm SD for each group. $\star P<0.001$. (E) FACS analysis of CD11b cells after exposure of THP-1 cells to ASLAN003 or DMSO for $24 \mathrm{~h}$ and $48 \mathrm{~h}$. The data display the mean \pm SD of three different experiments. ${ }^{*} P<0.001$ 
ASLAN003 and brequinar on AML cells over normal $\mathrm{CD} 34^{+} \mathrm{CD}_{38}{ }^{+} \mathrm{BM}$ cells obtained from healthy donors. $\mathrm{CD} 34^{+} \mathrm{CD} 38^{+}$cells are considered as dividing myeloid progenitor cells. The $\mathrm{IC}_{50}$ values of ASLAN003 and brequinar were $5.22 \mu \mathrm{M}$ and $2.87 \mu \mathrm{M}$, respectively (Online Supplementary Figure S1A). ASLAN003 and brequinar were on average 11 -fold more active in AML cells than in normal CD $34^{+} \mathrm{CD} 38^{+} \mathrm{BM}$ myeloid progenitor cells, suggesting a favorable therapeutic index for DHODH inhibitors.

Next we examined the differentiation effects of ASLAN003 on THP-1, MOLM-14 and KG-1 cells. Treatment of these leukemic cells with ASLAN003 consistently resulted in a substantial increase of CD11b in all three cell lines. The CD11 $\mathrm{b}^{+}$population was increased by $86.7 \%, 63.9 \%$ and $86.5 \%$ in THP-1, MOLM-14 and KG-1 cells treated with $100 \mathrm{nM}$ ASLAN003 after normalization to values for DMSO-treated samples $(P<0.001)$ (Figure $1 \mathrm{~B}$, Online Supplementary Figure S1B). CD14+ cells were also significantly increased in MOLM-14, THP-1 and KG-1 cells following treatment with ASLAN003 $(P<0.01)$ (Figure 1B, Online Supplementary Figure S1B). Secondly, cells treated with ASLAN003 displayed morphological changes with a lower nucleocytoplasmic ratio, condensed chromatin, and increased nuclear lobulation, which are characteristics of myeloid maturation (Figure 1C). Thirdly, we employed a NBT reduction assay to evaluate functional evidence of myeloid maturation. After $96 \mathrm{~h}$ of treatment with ASLAN003 $100 \mathrm{nM}, 95.2 \%$ of the THP-1 cells, $62.4 \%$ of the MOLM-14 cells, and $93.6 \%$ of the KG-1 cells were positive for NBT reduction $(P<0.001)$. At concentrations of ASLAN003 as low as $50 \mathrm{nM}$, more than $50 \%$ of the THP-1 cells showed increased NBT reduction compared with DMSO controls $(P<0.001)$ (Figure 1D). Furthermore, in a time-dependent experiment, following 24 or $48 \mathrm{~h}$ exposure to $100 \mathrm{nM}$ ASLAN003, almost $100 \%$ of THP-1 cells became CD11b+ (Figure 1E, Online Supplementary Figure S1C). Taken together, these results suggest that ASLAN003 can rapidly induce differentiation of AML cells.

\section{Differentiation effect of ASLAN003 and brequinar as well as uridine rescue}

Parallel experiments were carried out to compare the efficacy of ASLAN003 and brequinar. MOLM-14 cells were incubated with brequinar or ASLAN003 100 nM, a concentration similar to the half maximal effective concentration ( $\mathrm{EC}_{50}$ ) of ASLAN003 in MOLM-14 cells, for 96 h. After normalization to the respective controls, MOLM14 cells treated with brequinar had $33.1 \%$ of $\mathrm{CD}^{11} \mathrm{~b}^{+}$cells, while those treated with the same dose of ASLAN003 had $63.9 \%$ of $\mathrm{CD} 11 \mathrm{~b}^{+}$cells (Figure 2A, Online Supplementary Figure S1D). These results showed a nearly two-fold higher potency of ASLAN003 compared to brequinar $(P<0.05)$.

Because DHODH coverts dihydroorotate into orotate, which is a precursor of uridine, inhibition of DHODH leads to a diminished uridine pool in cells. ${ }^{16}$ In both MOLM-14 and THP-1 cells, ASLAN003-mediated differentiation was completely rescued by addition of $50 \mu \mathrm{M}$ uridine (Figure 2B), with no significant further rescue detected in the presence of higher concentrations of uridine $(100 \mu \mathrm{M}$ and $150 \mu \mathrm{M})$ (data not shown). Interestingly, uridine also rescued the cell viability of ASLAN003-treated MOLM-14 and THP-1 cells $(P<0.05)$ (Figure 2C). Overall, these data demonstrate that uridine could abrogate the effects of ASLAN003 on cell differentiation and cell viability, implying the on-target specificity of ASLAN003.

\section{ASLAN003 decreases viability and induces differentiation in primary acute myeloid leukemia blasts and myelodysplastic syndrome samples}

To confirm the clinical relevance of our observations in human AML cell lines, we examined the effect of ASLAN003 on cell viability and differentiation status in BM cells obtained from patients with de novo or relapsed AML and myelodysplastic syndrome (MDS). ASLAN003 displayed excellent potency in inducing differentiation and cell death in some primary AML blasts. For example, in patient UPN1 with AML-M1 with $\mathrm{t}(9 ; 22)$ and a complex karyotype, exposure to ASLAN003 at the concentrations of $2 \mu \mathrm{M}$ and $4 \mu \mathrm{M}$ led, respectively, to $22 \%$ and $30 \%$ increases in $\mathrm{CD} 11 \mathrm{~b}^{+}$cells, as well as $31 \%$ and $35 \%$ increases in $\mathrm{CD}_{14}{ }^{+}$cells. Concomitantly, there were decreases of $18 \%$ and $27 \%$, respectively, in cell viability. Furthermore, in patient UPN6 with AML-M2 with FLT3ITD and NPM1 mutations, following incubation with ASLAN003 $2 \mu \mathrm{M}$ and $4 \mu \mathrm{M}$ for $96 \mathrm{~h}$, we observed $18 \%$ and $23 \%$ more CD13/CD33 double positive cells, accompanying reduced cell viability. Among these tested samples, UNP5 with deletion of chromosome 7 had the most sensitive response, with the $\mathrm{CD} 11 \mathrm{~b}^{+}$population increasing by $62 \%$ in response to ASLAN003 $1 \mu \mathrm{M}$. Importantly, ASLAN003 was still effective in promoting differentiation and cell death of myeloid cells in relapsed AML (UNP13). Morphological analysis and NBT assays demonstrated the features of neutrophil differentiation in ASLAN003-treated AML blasts from selected cases (Online Supplementary Figure S2). In summary, the response of primary BM cells from AML patients to ASLAN003 was classified into three categories: sensitive if any of the myeloid markers CD11b, CD14, CD13 or CD33 increased $\geq 15 \%$; moderately sensitive if the markers increased $\geq 5 \%$, but $<15 \%$; and resistant if the markers did not increase or increased $<5 \%$. Among the AML samples, we observed six (43\%) sensitive cases, six $(43 \%)$ moderately sensitive cases and two $(14 \%)$ resistant cases (Table 1).

For BM samples from MDS patients, three cases $(50 \%)$ were sensitive to ASLAN003 and three cases (50\%) were moderately sensitive (Table 1). Thus, on the bases of these data, MDS cells appear to be sensitive to ASLAN003 treatment. No resistant cases were seen, but the number of cases tested was limited.

Notably, ASLAN003, at the concentrations of $2 \mu \mathrm{M}$ and $4 \mu \mathrm{M}$, was shown to have a negligible impact on cell viability and differentiation status of mononuclear cells from a healthy donor, suggesting that ASLAN003 is not toxic to normal hematopoietic cells (Table 1). Collectively, these experiments provide evidence that ASLAN003 treatment of primary cells obtained from either de novo or relapsed patients leads to myeloid differentiation and cell death.

\section{Transcriptome analysis reveals the effects of ASLAN003 on apoptosis, differentiation, metabolism and translation initiation in acute myeloid leukemia cells}

To understand the impact of ASLAN003 on transcriptional networks in AML, we performed RNA-sequencing on DMSO- and ASLAN003-treated KG-1 and MOLM-14 cells. These cells shared 320 upregulated genes and 225 downregulated genes (posterior probability of differential 
expression: 0.95-1, fold-change cutoff: 1.5) (Figure 3A, Online Supplementary Table S2). We then manually classified the list of genes. Among the genes upregulated by ASLAN003, 27 (8.4\%) were related to myeloid differentiation, $15(4.7 \%)$ were cell surface antigens, and $8(2.5 \%)$ were associated with apoptosis (Figure 3B). The downregulated gene list was particularly enriched with 49 ribosome family genes $(19.6 \%)$ and 21 metabolism-related genes $(8.4 \%)$ (Figure $3 \mathrm{~B})$. The gene expression changes of selected genes associated with apoptosis and myeloid differentiation were confirmed by qRT-PCR analysis (Figure
3C). Single-sample gene set enrichment analysis showed significant enrichment of "myeloid differentiation_up", "hematopoietic stem cell_down", "targets of HoxA9 and Meis1_down" signatures, and suppression of "pyrimidine ribonucleoside triphosphate metabolic process" (Figure 3D). These signatures were aligned with the observed effects of ASLAN003. The gene ontology term analysis revealed that upregulated genes were involved in cellular response to "neutrophil degranulation", "neutrophil mediated immunity", "positive regulation of caspase activity", "positive regulation of apoptosis", "regulation of extrinsic

A
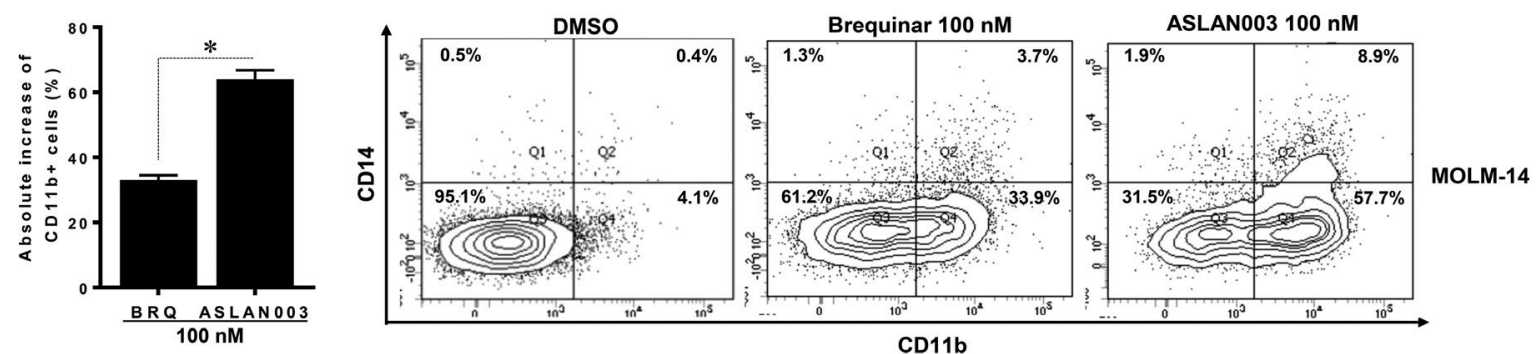

B
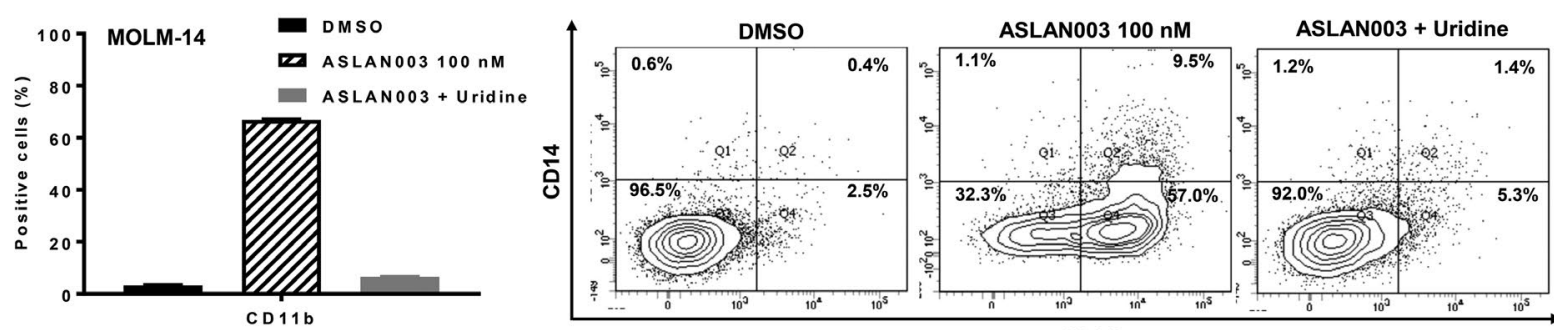

MOLM-14
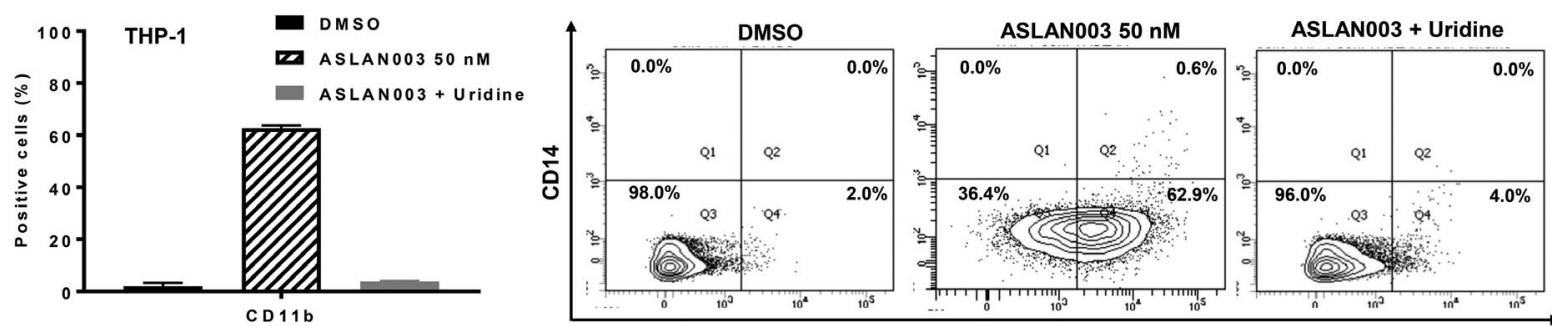

C
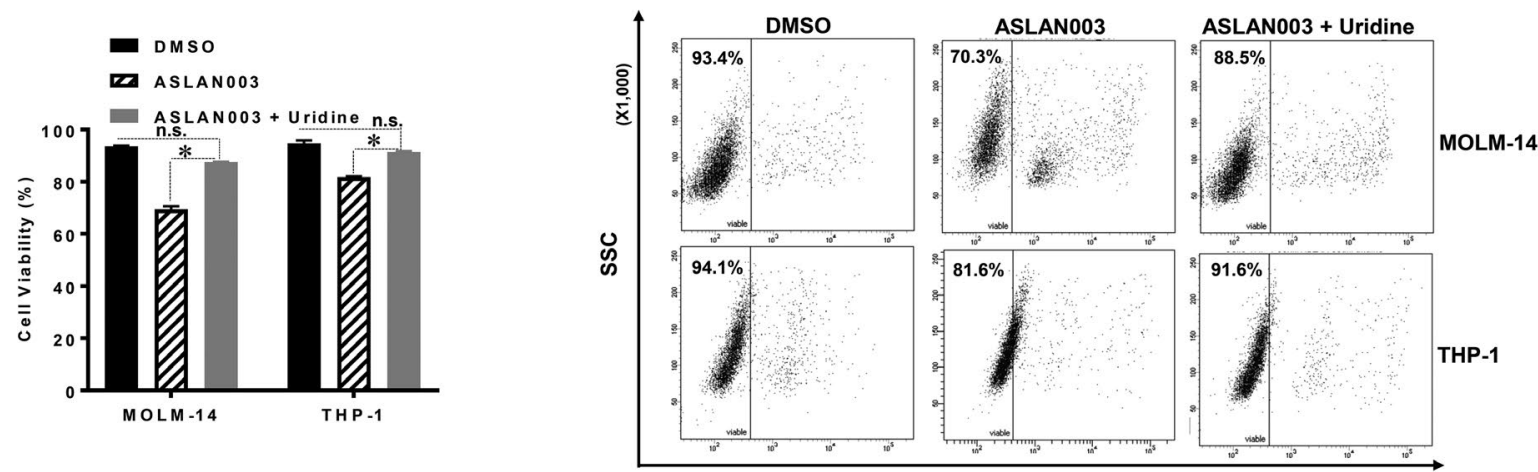

Pacific blue

Figure 2. Comparing ASLAN003 versus brequinar and the effect of uridine on cell differentiation by ASLAN003. (A) Comparison between the effects of 100 nM ASLANO03 and $100 \mathrm{nM}$ brequinar on differentiation of MOLM-14 cells. The absolute increase of CD11 $\mathrm{b}^{+}$cells was calculated based on the percentage of CD11 $\mathrm{b}^{+}$ cells increased in treated samples compared to control samples exposed to dimethylsulfoxide (DMSO). Representative FACS plots are shown. (B, C) Supplementation of uridine blocks ASLAN003-induced differentiation (B) and cell death (C) in MOLM-14 and THP-1 cells. Leukemic cells were incubated with DMSO, ASLANO03, or ASLAN003 + 50 uM uridine. ASLAN003 was used at a concentration of $100 \mathrm{nM}$ for MOLM-14 cells and $50 \mathrm{nM}$ for THP-1 cells. The percentages of CD11 $\mathrm{b}^{+}$cells (B) or viable cells $(C)$ are illustrated and representative FACS plots are shown. The data were based on triplicate different experiments (mean \pm standard deviation). $\star P<0.05$; n.s.: not significant. 
apoptosis" and "positive regulation of myeloid cell differentiation", while downregulated genes associated with "co-translational protein targeting to membrane", "rRNA metabolic process", "ribosome biogenesis", "translation" and "peptide biosynthetic process", showed the most significant changes (Figure $3 \mathrm{E}$ ). These data from transcriptome analysis suggest that ASLAN003 might impair protein synthesis and induce the differentiation and apoptosis transcriptional program in AML cells.

\section{ASLAN003 triggers apoptotic pathways}

Fas (CD95, APO-1) belongs to the cell death receptor family. Upon binding to its ligand FasL, they form deathinducing signaling complex (DISC), initiating the extrinsic apoptosis cascade. ${ }^{22}$ Our RNA-sequencing data showed that the expression of FAS was upregulated after treatment (Figure 3B, C, Online Supplementary Table S2), suggesting that ASLAN003 could trigger the extrinsic apoptosis pathway. Indeed, western blot analysis revealed a significant increase in cleaved caspase 8 , the extrinsic pathway-specific caspase, in ASLAN003-treated KG-1 and MOLM-14 cells (Figure 4A).

Because DHODH is located on the inner mitochondrial membrane, we also assessed whether ASLAN003 could induce loss of mitochondrial membrane potential $(\Delta \Psi \mathrm{m})$, an indicator of the early phase of intrinsic (mitochondrial or BCL-2-regulated) apoptosis. In the DMSO-treated cells, the majority of cells had intact mitochondrial membranes. ASLAN003 was found to disrupt $\Delta \Psi \mathrm{m}$ in a dose-depen- dent manner in THP-1, MOLM-14 and KG-1 cells (Figure $4 \mathrm{~B})$. To investigate whether loss of $\Delta \Psi \mathrm{m}$ is $\mathrm{DHODH}$-specific, we conducted mitochondrial membrane potential assays in MOLM-14 cells treated with brequinar, another $\mathrm{DHODH}$ inhibitor and cytarabine, a chemotherapeutic agent. Both brequinar and cytarabine could induce loss of $\Delta \Psi \mathrm{m}$ (Online Supplementary Figure S3), suggesting that loss of $\Delta \Psi \mathrm{m}$ is not DHODH-specific, most likely being a marker of cell health. However, given the localization of $\mathrm{DHODH}$, the effect of its inhibitors on mitochondrial membrane potential might be direct, while the effect of cytarabine might be indirect. As a result of loss of $\Delta \Psi \mathrm{m}$, increased leakage of cytochrome $\mathrm{c}$ from mitochondria into the cytosol, a characteristic of activation of the intrinsic apoptosis pathway, was also observed in ASLAN003treated cells (Figure 4A). ASLAN003 treatment also induced cleaved caspase-3 and -7 (Figure 4A). Altogether, these results suggest a role for both intrinsic and extrinsic pathways in ASLAN003-induced apoptosis.

\section{ASLAN003 inhibits protein synthesis and induces differentiation of acute myeloid leukemia cells via activation of AP-1 transcription factors}

Transcriptome and gene ontology analysis showed a greater enrichment of protein translation-related genes and ribosome proteins among the genes downregulated by ASLAN003. Furthermore, gene expression of four members of the family of eukaryotic translation initiation factors (eIF), namely EEF1B2, EIF4B, EIF3L, and EEF1B2P3,

Table 1. Clinical characteristics of patients with acute myeloid leukemia and myelodysplastic syndrome and their responses to ASLAN003 in an ex vivo assay.

\begin{tabular}{|c|c|c|c|c|c|}
\hline Response group & Diagnosis & Karyotype & FLT3 & NPM1 & Patient DD \\
\hline \multirow{9}{*}{$\begin{array}{l}\text { Highly sensitive } \\
\text { AML (43\%) } \\
\text { MDS (50\%) }\end{array}$} & AML-M1 & $\mathrm{t}(9 ; 22)$ & WT & WT & UPN1 \\
\hline & AML-M5 & Normal & WT & WT & UPN4 \\
\hline & AML-M2 & +8 & ITD & Mutant & UPN6 \\
\hline & AML with MDS & $\mathrm{t}(8 ; 21)$ & NA & NA & UPN7 \\
\hline & AML-M5 & Normal & NA & NA & UPN9 \\
\hline & AML-M4 & -7 & WT & WT & UPN5 \\
\hline & MDS & Normal & NA & NA & UPN16 \\
\hline & MDS & Normal & $\mathrm{NA}$ & $\mathrm{NA}$ & UPN17 \\
\hline & MDS & Complex & NA & NA & UPN18 \\
\hline \multirow{9}{*}{$\begin{array}{l}\text { Moderately sensitive } \\
\text { AML (43\%) } \\
\text { MDS (50\%) }\end{array}$} & AML-M2 & Normal & TKD & NA & UPN2 \\
\hline & AML-M1 & -9 & NA & $\mathrm{NA}$ & UPN8 \\
\hline & AML-M4 & Normal & WT & WT & UPN11 \\
\hline & Relapsed AML & +13 & ITD & $\mathrm{NA}$ & UPN12 \\
\hline & AML-M4 & $\operatorname{Inv}(16)$ & TKD & WT & UPN10 \\
\hline & AML-M4 & $\operatorname{Inv}(16)$ & ITD & WT & UPN13 \\
\hline & MDS & Normal & NA & $\mathrm{NA}$ & UPN15 \\
\hline & MDS & -7 & WT & WT & UPN19 \\
\hline & MDS & $-13,+8$ & $\mathrm{NA}$ & NA & UPN20 \\
\hline \multirow{3}{*}{$\begin{array}{l}\text { Resistant } \\
\text { AML (14\%) }\end{array}$} & AML-M5a & +8 & TKD & Mutant & UPN3 \\
\hline & AML-M1 & +11 & WT & WT & UPN14 \\
\hline & Healthy donor & Normal & WT & WT & \\
\hline
\end{tabular}

The response of primary bone marrow cells to ASLAN003 was classified into three categories: sensitive if any of myeloid markers CD11b, CD14, CD13 or CD33 increased $\geq 15 \%$; moderately sensitive if the markers increased $\geq 5 \%$, but $<15 \%$; and resistant if the markers increased $<5 \%$, by FACS analysis. FLT3: fms-like tyrosine kinase; NPM: nucleophosmin- 1 ; ID: identify;AML: acute myeloid leukemia; MDS: myelodysplastic syndromes; WT: wildtype; UPD: unique patient number; ITD: internal tandem duplication; NA; not available;TKD: tyrosine kinase domain. 

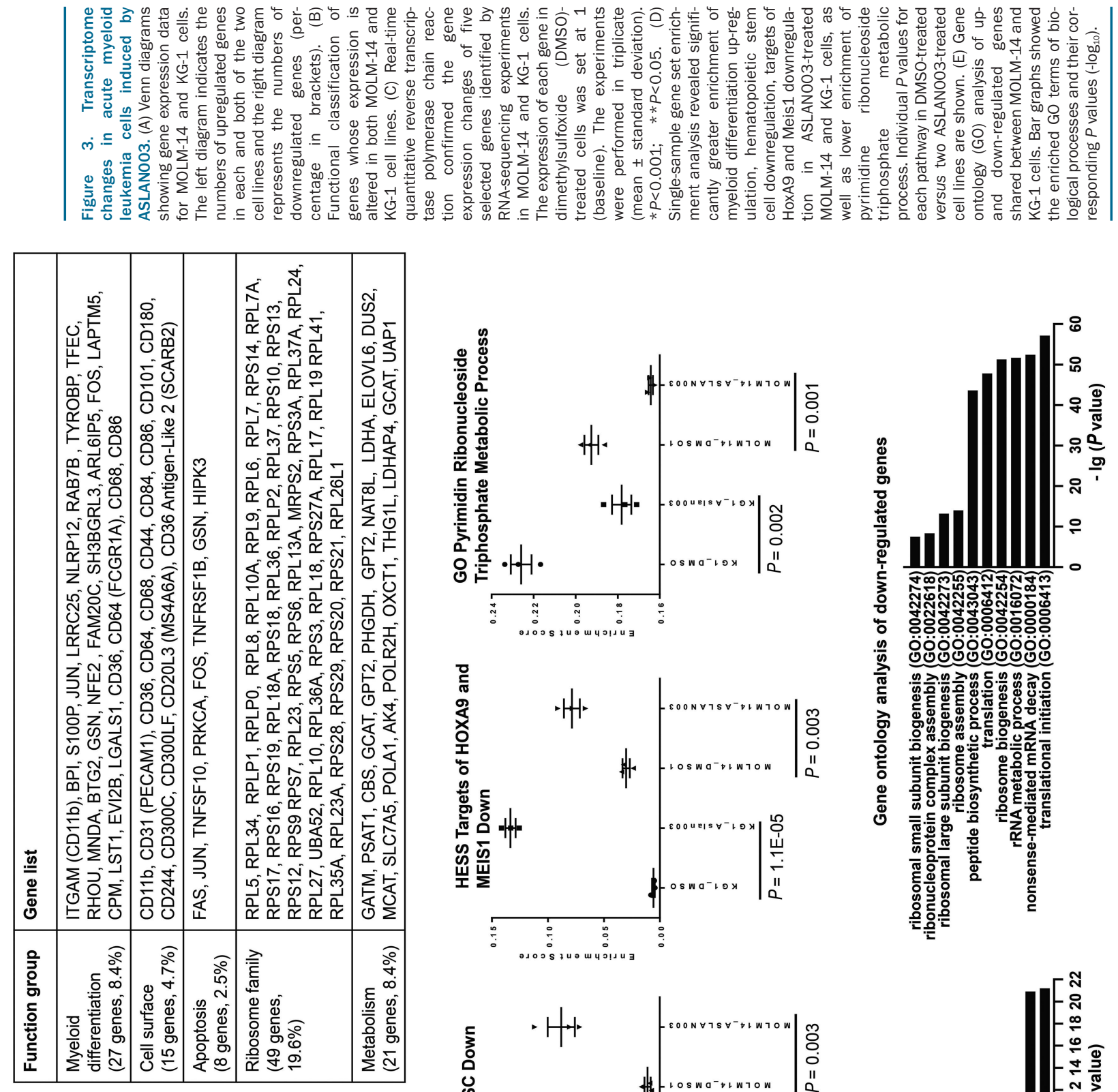

$\infty$
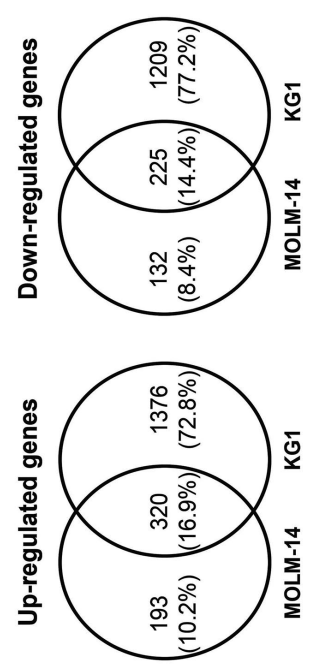
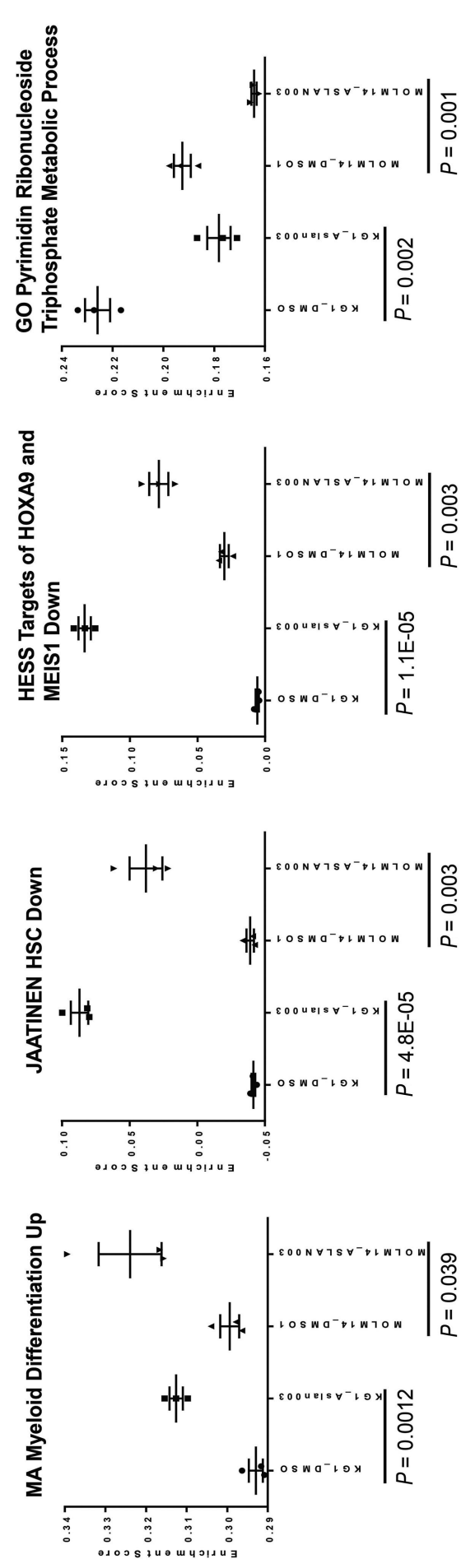
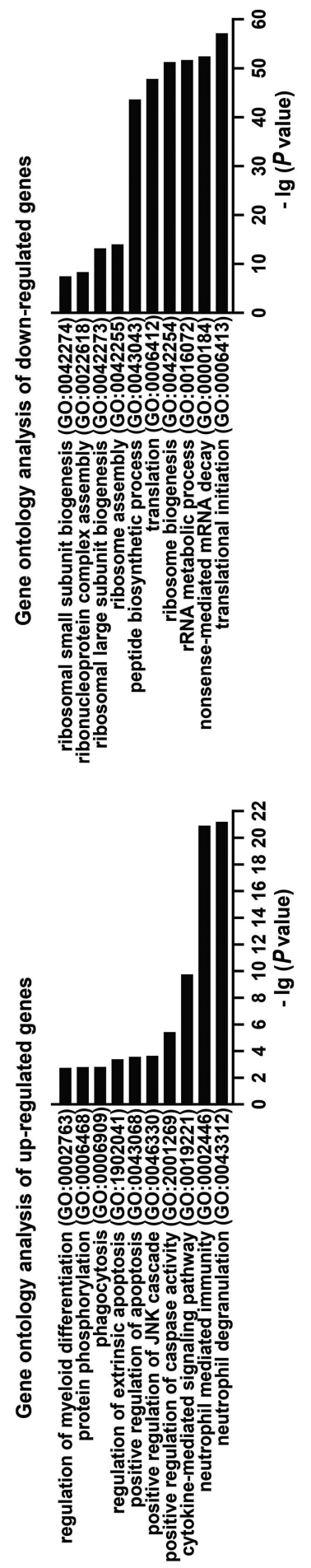

0

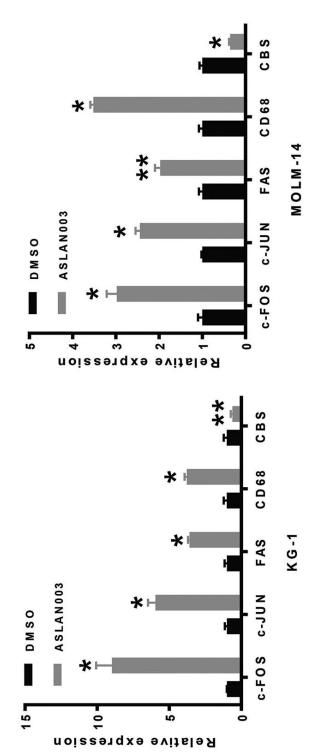

口

ш 
A

\begin{tabular}{|c|c|c|c|}
\hline & KG-1 & MOLM-14 & \multirow{7}{*}{ 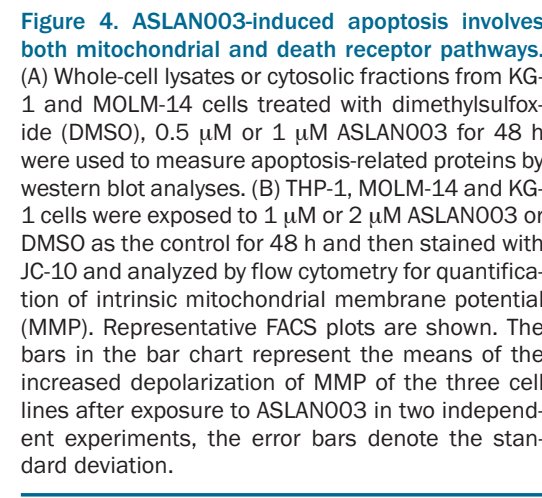 } \\
\hline ASLAN003 ( $\mu \mathrm{M})$ & 0.5 & $\begin{array}{ll}0.5 & 1\end{array}$ & \\
\hline Cleaved-Caspase 3 & 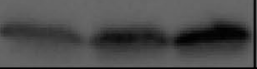 & $m-m$ & \\
\hline Cleaved-Caspase 7 & - & $=0$ & \\
\hline $\begin{array}{r}\text { Cytosolic } \\
\text { Cytochrome c }\end{array}$ & & & \\
\hline $\begin{array}{l}\text { Cytosolic } \\
\text { GAPDH }\end{array}$ & & & \\
\hline aved-Caspase 8 & & & \\
\hline
\end{tabular}

GAPDH

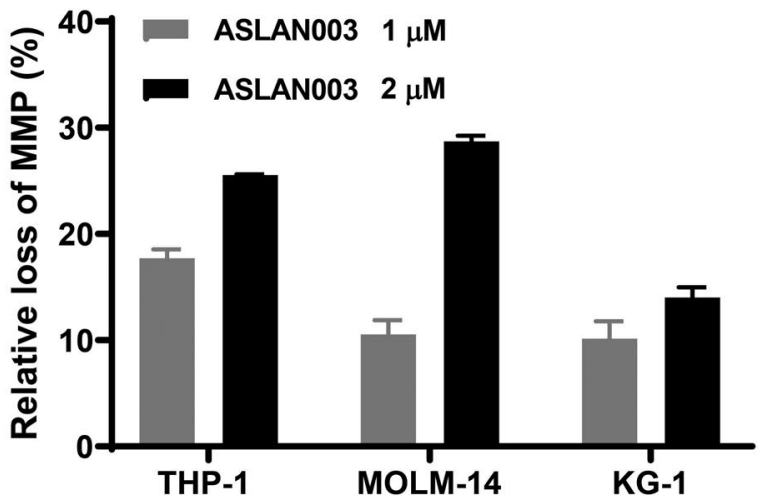

B

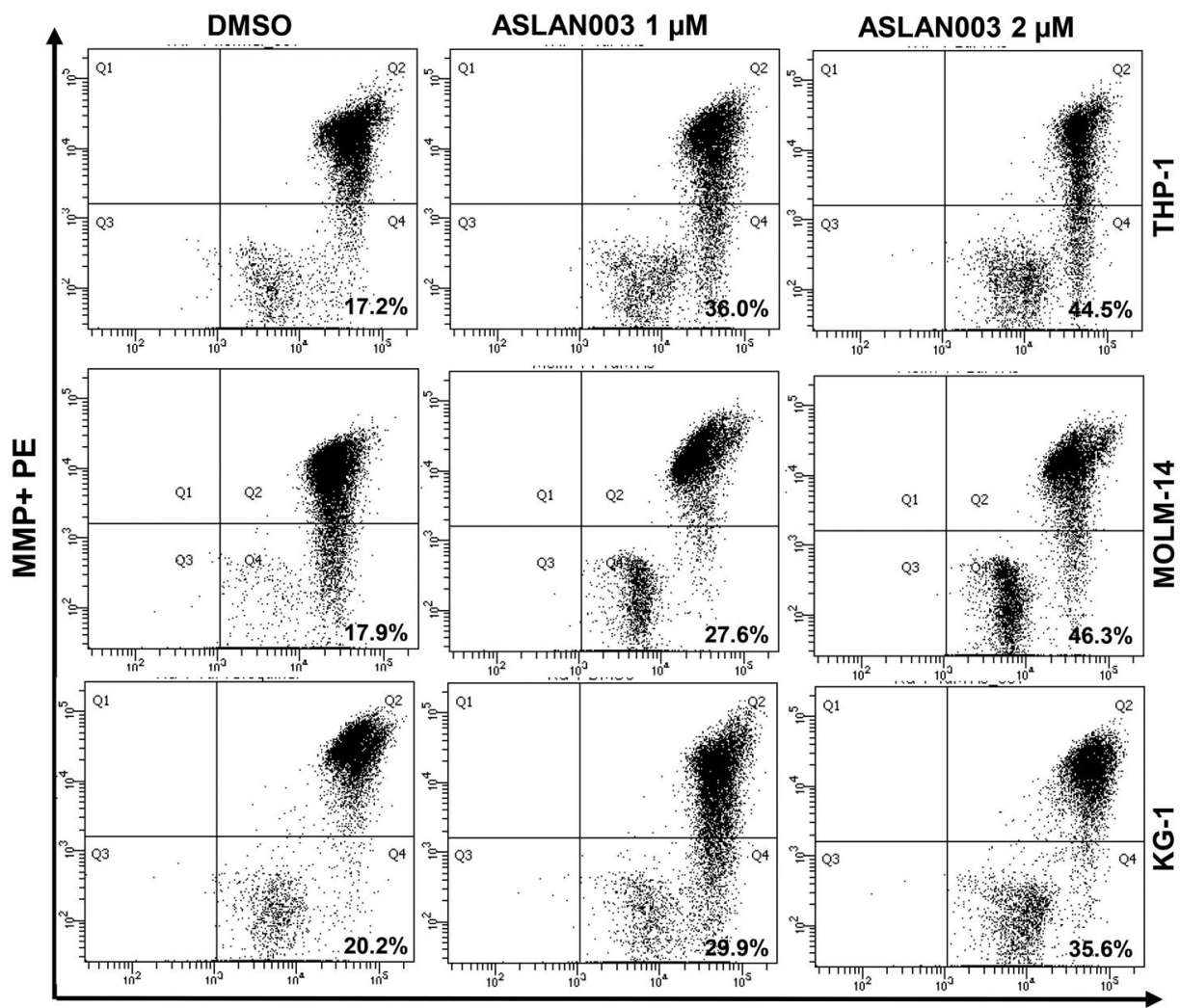

Loss of MMP FITC 
were significantly decreased in ASLAN003-treated cells (Online Supplementary Table S2). The eIF proteins are essential factors for protein synthesis, hence we performed an assay to determine the effects of ASLAN003 on protein synthesis. Indeed, ASLAN003 inhibited protein synthesis, as demonstrated by the reduced incorporation of OPP at protein translation sites in both MOLM-14 and KG-1 cells (Figure 5A). We also investigated proteins involved in the control of the mRNA translation process. In agreement with the RNA-sequencing data, western blot analysis confirmed the downregulation of EIF4B, and RPL6 proteins (Figure 5B)

As revealed by RNA-sequencing and qRT-PCR analysis, FOS and JUN were upregulated by ASLAN003. We, therefore, decided to delineate the role of activating protein 1 (AP-1) transcription factors in ASLAN003-mediated differentiation. Western blot analysis confirmed the dosedependent increase of c-FOS protein levels in response to exposure to ASLAN003 (Figure 5B). T-5224 is a selective, small-molecule inhibitor of AP- $1 .{ }^{23}$ Of note, T-5224 did not decrease cell viability when applied at doses of up to 125 $\mu \mathrm{M}$ in MOLM-14 and KG-1 cells (Online Supplementary Figure S4A). We then evaluated the effect of T-5224 on ASLAN003-mediated differentiation. Addition of $20 \mu \mathrm{M}$ T-5224 completely abolished the differentiation effect of ASLAN003 in KG-1 cells and dampened the effect by half in MOLM-14 cells (both $P<0.001$ ) (Figure 5C, Online Supplementary Figure S4B). T-5224 alone had a minimal effect on differentiation (Figure 5C). These results therefore suggest that ASLAN003-mediated differentiation is facilitated, at least partially, via activation of AP-1 transcription factors.

Robust in vivo efficacy of ASLAN003 in multiple mouse xenograft acute myeloid leukemia models

To determine in vivo efficacy of ASLAN003 in AML, we first used two mouse xenograft models of the human AML cell lines, MOLM-14, and THP-1. Treatment with ASLAN003 (50 mg/kg, once daily oral gavage) was well tolerated as evidenced by the fact that there were no significant differences in body weight, hemoglobin concentration or platelet counts between the vehicle control and treated groups in these two models (Online Supplementary Figure S5A). Survival was significantly prolonged in the ASLAN003-treated groups compared to the vehicle control groups in both xenograft models $(P=0.03$ and $P<0.001)$ (Figure 6A). In the MOLM-14 xenograft model, ASLAN003 substantially reduced the number of disseminated tumors, but also the size of these tumors relative to those in controls (Online Supplementary Figure S5B). Interestingly, in the THP-1 xenograft model, we observed that the livers of control mice were swollen and the surfaces were covered by copious white dots, a manifestation of leukemic infiltration. In sharp contrast, the appearance and size of the livers remained largely normal in ASLAN003-treated mice bearing THP-1 cells (Online Supplementary Figure S5B). Taken
A

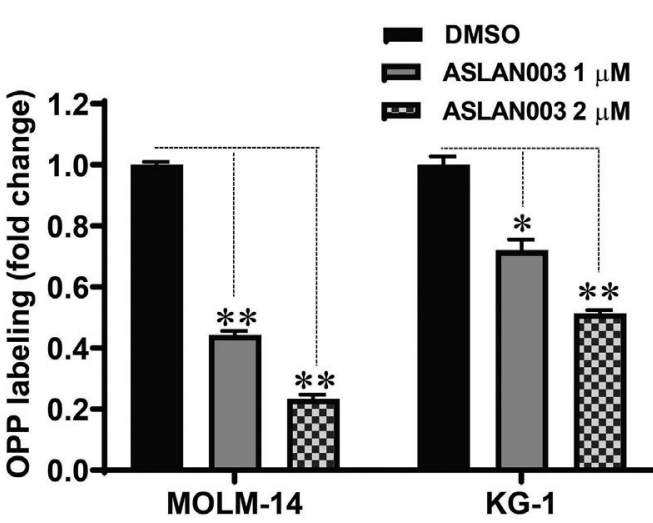

B

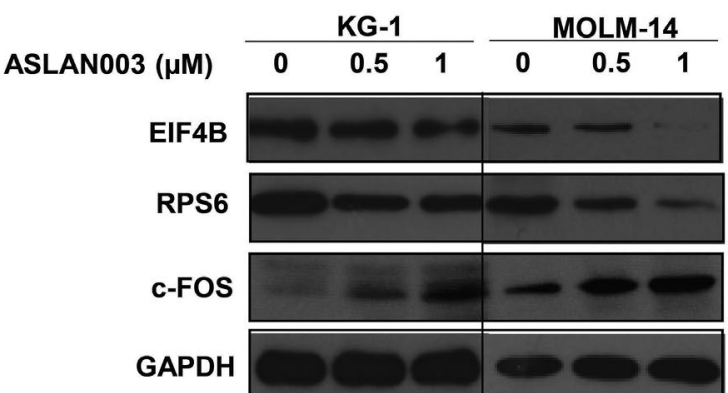

C
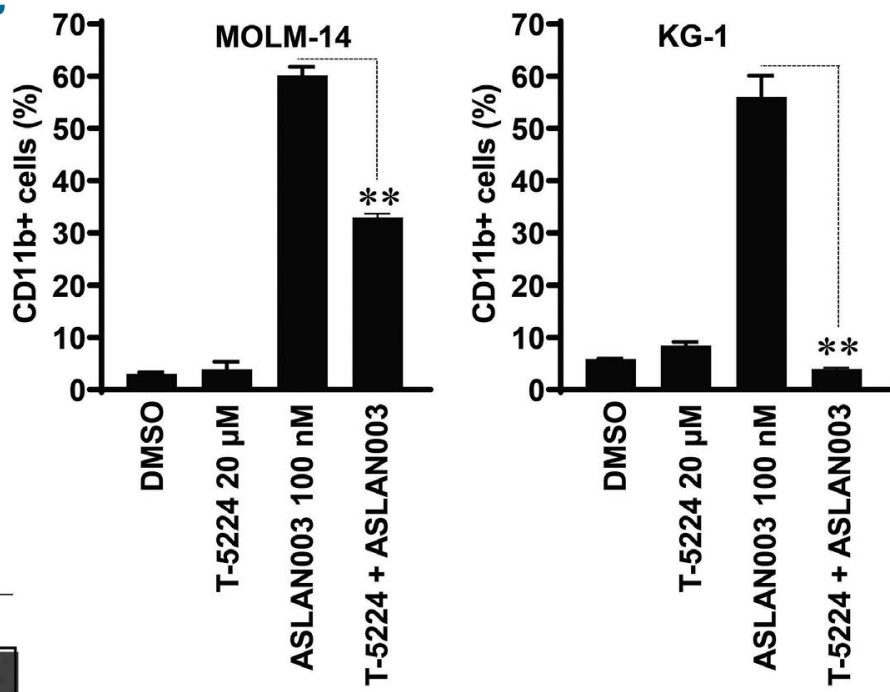

Figure 5. Effects of ASLANO03 on protein synthesis and AP-1 transcription factors. (A) MOLM-14 and KG-1 cells were incubated with ASLANO03 at the doses of 1 $\mu \mathrm{M}$ and $2 \mu \mathrm{M}$ for $1 \mathrm{~h}$ before addition of O-propargyl-puromycin (OPP) reagent for $1 \mathrm{~h}$, followed by flow cytometry analyses. The graph represents fold decreases in OPP labeling [means \pm standard deviation (SD) $(n=3)$ in MOLM-14 and KG-1 cells, with values for dimethylsulfoxide (DMSO)-treated cells set at 1.0. Statistical comparisons between groups are shown (Student $t$-test). $* P<0.05$; $* * P<0.01$. (B) Immunoblotting analysis of whole cell lysates extracted from KG-1 and MOLM-14 cells for markers as indicated. The treatment time was $48 \mathrm{~h}$. GAPDH was used as a loading control. (C) MOLM-14 and KG-1 cells were treated with ASLANO03 alone, T5224 alone, the two drugs in combination, or DMSO as a control, for $96 \mathrm{~h}$, and then subjected to FACS quantification of human CD11b antigen. The graphs show the percentage of the $\mathrm{CD} 11 \mathrm{~b}^{+}$population $(n=2$, mean $\pm \mathrm{SD}$ ). Statistical comparisons between the effects of ASLAN003 as a single agent and in combination treatment are shown $(* * P<0.001)$. The percentage of $\mathrm{CD} 11 \mathrm{~b}^{+}$cells were not statistically different between DMSO- and T-5224-treated samples $(P>0.05)$. 
together, the therapeutic effects of ASLAN003 were multiple: prolonged survival, and prevention of tumor dissemination and leukemic infiltration into organs.

Next, we tested the in vivo effect of ASLAN003 on leukemic burden (human $\mathrm{CD} 45^{+}$cells) and differentiation (CD11b $b^{+}$or $\mathrm{CD}_{14} 4^{+}$cells). The numbers of human $\mathrm{CD} 45^{+}$ cells in BM, peripheral blood, spleen and liver were all significantly reduced in ASLAN003-treated mice compared to those in control mice in both models (Figure $6 \mathrm{~B}$ ). In agreement with in vitro observations, FACS analysis showed significantly increased numbers of $\mathrm{CD} 11 \mathrm{~b}^{+}$and $\mathrm{CD} 14^{+}$cells in BM of treated mice in both models (Figure $6 \mathrm{~B})$. Taken together, these experiments confirmed that ASLAN003 could induce differentiation and reduce leukemic burden in vivo.

We also evaluated the therapeutic efficacy of ASLAN003 in patient-derived AML xenografts. For AML14 , an indolent line, at the end of experiments all mice

A
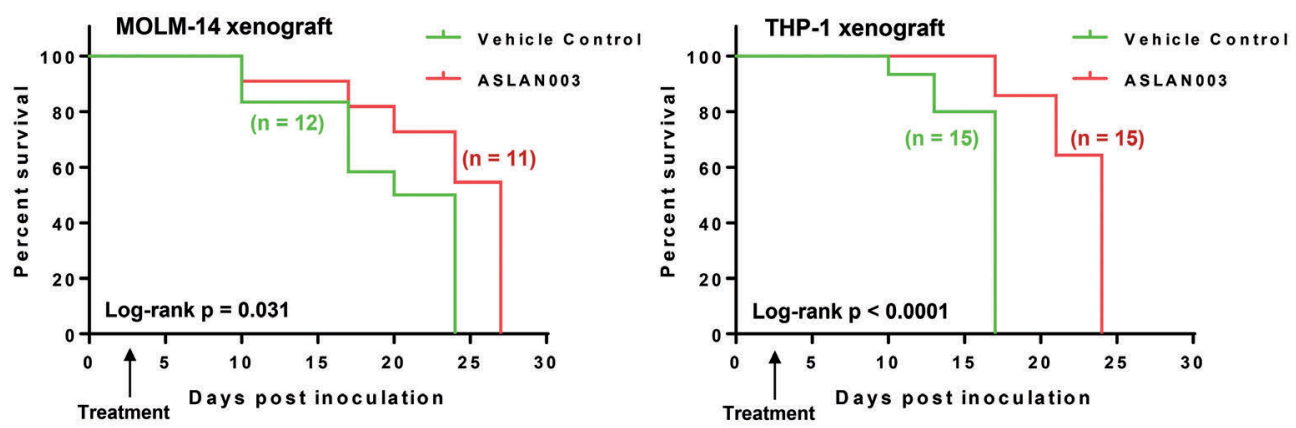

B
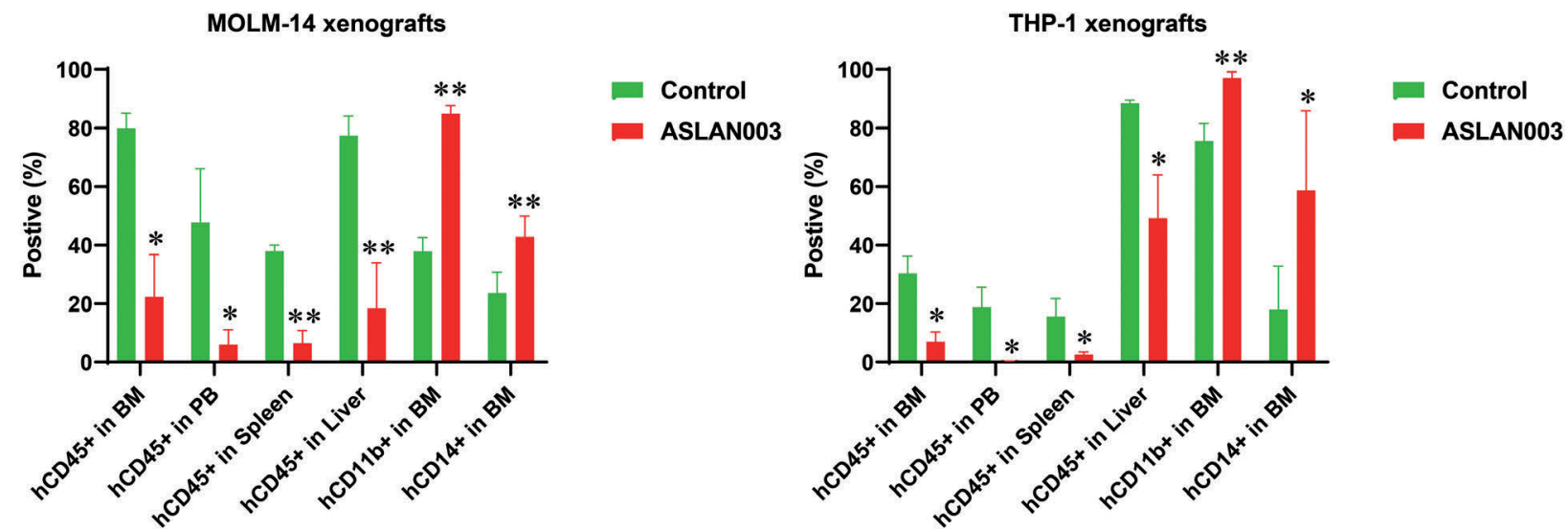

C

AML-14 PDX

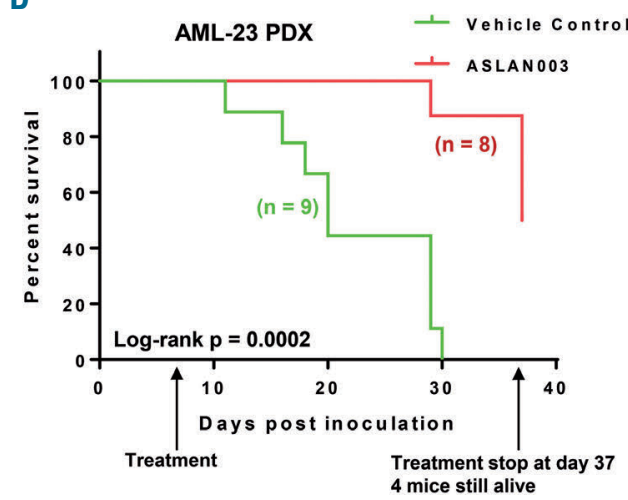

E

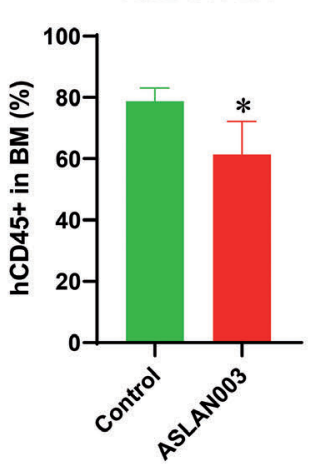

AML-23 PDX

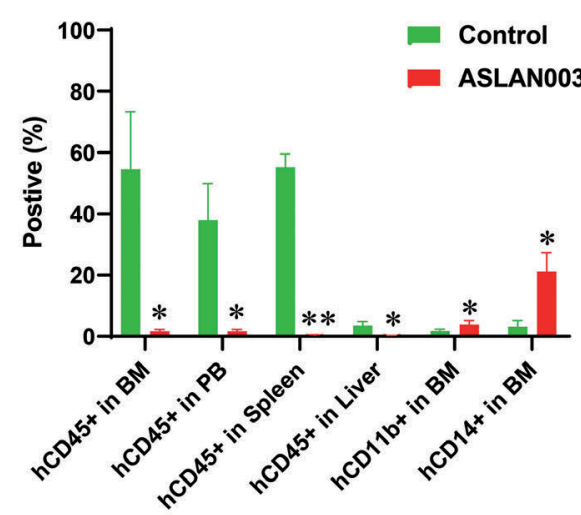

Figure 6. The in vivo efficacy of ASLANO03 in xenograft models. (A) Kaplan-Meier survival curves of mice treated with either ASLANO03 or vehicle control for the MOLM-14 and THP-1 xenograft models. Mice were administered either ASLAN003 $50 \mathrm{mg} / \mathrm{kg}$ or the same volume of the vehicle by daily oral gavage. Treatment was started 3 days after inoculation of leukemic cells. The number of mice in each group and log-rank $P$ values are indicated. (B) The leukemic burdens in mouse bone marrow (BM), peripheral blood (PB), spleen and liver were compared for the ASLANO03-treated and vehicle-treated groups for MOLM-14 xenograft models ( $\mathrm{n}=3$ ) and THP-1 models $(n=4)$. The number of human $C D 45^{+}$cells was determined by FACS analysis as a surrogate marker for leukemic burden. FACS analysis was performed to assess the percentage of human specific $C D 11 b^{+}, C D 14^{+}$leukemic cells in BM and PB samples harvested from these mice. $* P<0.05$; $* * P<0.01$. (C) FACS analysis of human $\mathrm{CD} 45^{+}$cells in BM samples harvested from mice with AML-14 patient-derived xenotransplants (PDX) treated with ASLAN003 or vehicle control $(n=4, * P=0.039)$. (D) Kaplan-Meier survival curves of animals with AML-23 PDX receiving ASLAN003 or control treatment. (E) FACS analysis was performed to assess the percentage of human specific $\mathrm{CD}_{4} 5^{+}$in $\mathrm{BM}, \mathrm{PB}$, spleen and liver, as well as $\mathrm{CD} 11 \mathrm{~b}^{+}, \mathrm{CD} 14^{+}$leukemic cells in BM samples harvested from mice with $\mathrm{AML}$ 23 PDX $(n=3) . * P<0.05$; **P<0.01. 
were alive and no obvious signs of disease were observed in either the control or ASLAN003 group. However, we found that the leukemic burden was significantly less in ASLAN003-treated PDX than in vehicle-treated PDX $(P=0.04)$ (Figure 6C). The weight of the mice increased gradually and similarly in both groups during the treatment $(P=0.42)$ (Online Supplementary Figure S5C). For AML-23, an aggressive PDX line, all animals with vehicletreated xenografts $(\mathrm{n}=9)$ succumbed to the disease within a month (median survival 20 days). In contrast, $50 \%$ of the animals with ASLAN003-treated PDX $(n=8)$ were still active and alive at the end of experiments on day 37 $(P=0.0002)$ (Figure 6D). Importantly, the percentages of human $C D 45^{+}$leukemia cells were significantly reduced in $\mathrm{BM}$, peripheral blood, spleen, and liver of the ASLAN003 group as compared to the control group. The in vivo differentiation effect of ASLAN003 was also confirmed by the observation of increased human CD11 $b^{+}$and CD14+ cells in $\mathrm{BM}$ (Figure $6 \mathrm{E}$ ). As for the AML-14 line, there was no statistical difference between the body weight of the AML-23 control group and the ASLAN003-treated group $(P=0.73)$ (Online Supplementary Figure S5C). Overall, these data demonstrate that ASLANO03 treatment mediates therapeutic efficacy in AML-PDX by extending survival, reducing leukemic burden and inducing differentiation. Notably, ASLAN003 appears safe and well tolerated even after prolonged in vivo administration.

\section{Discussion}

Recently, DHODH has been demonstrated to be a novel target for differentiation therapy in AML. ${ }^{24}$ Brequinar is the first DHODH inhibitor that has shown potency in inducing differentiation, but its clinical use is impeded by its hematologic toxicity and ineffectiveness in early trials in patients with solid tumors. . $^{1925,26}$ Several other DHODH inhibitors have been described. PTC299, an inhibitor of VEGFA mRNA translation, has also been shown to target DHODH and to have broad activity against hematologic cancer cells in a preclinical setting. ${ }^{27}$ Isobavachalcone, a natural product, has been reported to target $\mathrm{DHODH}$, resulting in apoptosis and differentiation of AML cell lines at a high concentration $(10 \mu \mathrm{M})$ in vitro. ${ }^{28}$ BAY 2402234, a novel DHODH inhibitor, induces differentiation and inhibits proliferation in multiple AML subtypes and is currently being evaluated in a phase I trial in myeloid malignancies. ${ }^{29}$

In this study, we comprehensively characterize ASLAN003, a novel, potent DHODH inhibitor. ASLAN003 induces massive differentiation of AML cell lines, as well as primary AML and MDS cells. ASLAN003 triggers apoptotic pathways in AML cell lines. Multiple mechanisms may account for these effects of ASLANO03 on leukemia cells. In general, myeloid leukemia cells have a higher proliferation rate compared to normal myeloid cells, thus requiring more energy (ATP) and abundant amounts of precursors for many biosynthetic pathways. The de novo biosynthesis of pyrimidine provides multiple essential precursors for such pathways. By targeting $\mathrm{DHODH}$, a key enzyme in pyrimidine biosynthesis, ASLAN003 significantly depletes pyrimidine nucleotides, leaving insufficient precursors for leukemia cells to biosynthesize DNA, RNA, and proteins. Consistently, our RNA-sequencing data revealed that a large family of genes associated with protein translation initiation was the top and the largest class downregulated by ASLAN003 treatment. We further experimentally validated that ASLAN003 inhibits protein synthesis in AML cells. A growing body of evidence supports a critical onco-addiction on active protein translation in AML cells. Aberrant protein translation contributes to arrested differentiation of myeloid cells and leukemogenesis. ${ }^{30,31}$ EIF4B, one member of the eIF family, is downregulated by ASLAN003. EIF4B has been found to stimulate translation of a particular set of genes with long, structured 5'-untranslated regions, such as $M Y C, B C L-2$, and XIAP, which promote cell survival and proliferation. ${ }^{32}$ Ribavirin, which blocks the binding of eIF4E to mRNA, has been shown to induce complete or partial remission in some relapsed AML patients. ${ }^{33}$

Notably, our study has determined that ASLAN003meditated AP-1 activation is important for the reversal of the blocked differentiation of AML cells. Transcription factors for AP-1 comprise several families of protein dimers, mainly JUN (c-Jun, JunB and JunD), FOS (c-Fos, FosB, Fra1, and Fra2) and ATF (ATFa, ATF-2, and ATF-3). ${ }^{34}$ It is known that AP-1 transcription factors are implicated in the differentiation of leukemia cells. ${ }^{35}$ Deletion of JunB in transgenic mice causes leukemogenic stem cell expansion, resulting in a myeloproliferative disorder which resembles early human chronic myelogenous leukemia. ${ }^{36}$ Early studies demonstrated that cytarabine treatment induced differentiation of AML cells and enhanced JUN/AP-1 activity was observed ${ }^{37}$ Overexpression of c-Fos overrides the blockage of differentiation mediated by c-Myc and potentiates interleukin-6-induced differentiation in AML cells. ${ }^{38}$ In agreement with these findings, our data indicate a vital role for AP-1 in ASLAN003-induced differentiation of AML. The differentiation effect of ASLAN003 is almost completely negated in KG-1 cells and partially abrogated in MOLM-14 cells by co-treatment with an AP-1 inhibitor, T-5224.

In further support of its clinical relevance, ASLAN003 induced primary AML blast myelocytic differentiation and decreased viability. It is worth noting that these therapeutic effects were achieved not only in samples from patients with de novo AML, but also in samples from patients with relapsed disease. In our study, a once daily dose of ASLAN003 $50 \mathrm{mg} / \mathrm{kg}$ for 2 to 11 weeks in two AML cell line xenografts and two PDX models of NSG mice did not affect the animals' body weight, indicating that the drug is safe and well-tolerated.

In summary, our study demonstrates that ASLAN003 is a novel, potent DHODH inhibitor characterized by antiAML efficacy in vitro and in vivo and remarkable tolerability. We also provide molecular mechanisms through which ASLAN003 exerts multiple actions, including induction of apoptotic pathways, inhibition of protein translation and activation of AP-1 transcription factors. Taken together, our findings support the further development of ASLAN003 for clinical use in AML, a disease for which novel therapies are much needed. ASLAN003 has been granted orphan drug designation for the treatment of AML by the Food and Drug Administration and is currently being evaluated in a phase IIa trial in AML (ClinicalTrials.gov: NCT03451084).

\section{Acknowledgments}

This work was supported by a research fund from ASLAN Pharmaceuticals and the Singapore National Research 
Foundation and the Ministry of Education under the Research Center of Excellence Program to WJC and NMRC ClinicianScientist IRG Grant CNIG11nov38 (to JZ). WJC is also supported by a NMRC Clinician Scientist Investigator award.
This study is also partially supported by the RNA Biology Center at CSI Singapore, NUS, by funding with Singapore Ministry of Education's Tier 3 grants, grant number MOE2014-T3-1-006.

\section{References}

1. Heidel FH, Mar BG, Armstrong SA. Selfrenewal related signaling in myeloid leukemia stem cells. Int $\mathrm{J}$ Hematol. 2011;94(2):109-117.

2. Mack EKM, Marquardt A, Langer D, et al. Comprehensive genetic diagnosis of acute myeloid leukemia by next-generation sequencing. Haematologica. 2019;104(2): 277-287.

3. Misaghian N, Ligresti G, Steelman LS, et al. Targeting the leukemic stem cell: the Holy Grail of leukemia therapy. Leukemia. 2009;23(1):25-42.

4. Zhou J, Chng WJ. Identification and targeting leukemia stem cells: the path to the cure for acute myeloid leukemia. World J Stem Cells. 2014;6(4):473-484

5. Zelent A, Guidez F, Melnick A, Waxman S, Licht JD. Translocations of the RARalpha gene in acute promyelocytic leukemia. Oncogene. 2001;20(49):7186-7203

6. Fasan A, Haferlach C, Perglerova K, Kern W, Haferlach T. Molecular landscape of acute promyelocytic leukemia at diagnosis and relapse. Haematologica. 2017;102(6):e222e224.

7. Wang ZY, Chen Z. Acute promyelocytic leukemia: from highly fatal to highly curable. Blood. 2008;111(5):2505-2515

8. Nowak D, Stewart D, Koeffler HP. Differentiation therapy of leukemia: 3 decades of development. Blood. 2009;113 (16):3655-3665

9. Tenen DG. Disruption of differentiation in human cancer: AML shows the way. Nat Rev Cancer. 2003 ;3(2):89-101.

10. Stein EM, DiNardo CD, Pollyea DA, et al. Enasidenib in mutant IDH2 relapsed or refractory acute myeloid leukemia. Blood. 2017;130(6):722-731.

11. Huang M, Graves LM. De novo synthesis of pyrimidine nucleotides; emerging interfaces with signal transduction pathways. Cell Mol Life Sci. 2003;60(2):321-336.

12. Reis RAG, Calil FA, Feliciano PR, Pinheiro MP, Nonato MC. The dihydroorotate dehydrogenases: past and present. Arch Biochem Biophys. 2017;632:175-191

13. Evans DR, Guy HI. Mammalian pyrimidine biosynthesis: fresh insights into an ancient pathway. J Biol Chem. 2004;279(32):3303533038.

14. Bar-Or A, Pachner A, Menguy-Vacheron F, Kaplan J, Wiendl H. Teriflunomide and its mechanism of action in multiple sclerosis.
Drugs. 2014;74(6):659-674

15. Lolli ML, Sainas S, Pippione AC, et al. Use of human dihydroorotate dehydrogenase (hDHODH) inhibitors in autoimmune diseases and new perspectives in cancer therapy. Recent Pat Anticancer Drug Discov. 2018;13(1):86-105.

16. Munier-Lehmann $\mathrm{H}$, Vidalain PO, Tangy $\mathrm{F}$, Janin YL. On dihydroorotate dehydrogenases and their inhibitors and uses. I Med Chem. 2013;56(8):3148-3167.

17. Sykes DB, Kfoury YS, Mercier FE, et al Inhibition of dihydroorotate dehydrogenase overcomes differentiation blockade in acute myeloid leukemia. Cell. 2016;167(1):171-186.

18. Dexter DL, Hesson DP, Ardecky RI, et al. Activity of a novel 4-quinolinecarboxylic acid, NSC 368390 [6-fluoro-2-(2'-fluoro-1,1'biphenyl-4-yl)-3-methyl-4-quinolinecarb oxylic acid sodium salt], against experimental tumors. Cancer Res. 1985;45(11 Pt 1):5563-5568.

19. Madak JT, Bankhead A 3rd, Cuthbertson CR, Showalter HD, Neamati N. Revisiting the role of dihydroorotate dehydrogenase as a therapeutic target for cancer. Pharmacol Ther. 2019;195:111-131.

20. Zhou J, Lu X, Tan TZ, Chng WJ. X-linked inhibitor of apoptosis inhibition sensitizes acute myeloid leukemia cell response to TRAIL and chemotherapy through potentiated induction of proapoptotic machinery. Mol Oncol. 2018;12(1):33-47.

21. Zhou J, Bi C, Janakakumara JV, et al. Enhanced activation of STAT pathways and overexpression of survivin confer resistance to FLT3 inhibitors and could be therapeutic targets in AML. Blood. 2009;113(17):4052 4062

22. Debatin KM, Stahnke K, Fulda S. Apoptosis in hematological disorders. Semin Cancer Biol. 2003;13(2):149-158.

23. Avouac J, Palumbo K, Tomcik $M$ et al Inhibition of activator protein 1 signaling abrogates transforming growth factor betamediated activation of fibroblasts and prevents experimental fibrosis. Arthritis Rheum. 2012;64(5):1642-1652.

24. Sykes DB. The emergence of dihydroorotate dehydrogenase (DHODH) as a therapeutic target in acute myeloid leukemia. Expert Opin Ther Targets. 2018;22(11):893-898.

25. Pally C, Smith D, Jaffee B, et al. Side effects of brequinar and brequinar analogues, in combination with cyclosporine, in the rat. Toxicology. 1998;127(1-3):207-222

26. Arteaga CL, Brown TD, Kuhn JG, et al. Phase I clinical and pharmacokinetic trial of brequinar sodium (DuP 785; NSC 368390). Cancer Res. 1989;49(16):4648-4653.

27. Cao L, Weetall M, Trotta C, et al. Targeting of hematologic malignancies with PTC299, a novel potent inhibitor of dihydroorotate dehydrogenase with favorable pharmaceutical properties. Mol Cancer Ther. 2019;18 (1):3-16.

28. Wu D, Wang W, Chen W, et al Pharmacological inhibition of dihydroorotate dehydrogenase induces apoptosis and differentiation in acute myeloid leukemia cells Haematologica. 2018;103(9):1472-1483

29. Christian S, Merz C, Evans L, et al. The novel dihydroorotate dehydrogenase (DHODH) inhibitor BAY 2402234 trigger differentiation and is effective in the treatment of myeloid malignancies. Leukemia. 2019;33(10):2403-2415

30. Girardi T, De Keersmaecker K. T-ALL: ALL a matter of translation? Haematologica. 2015;100(3):293-295.

31. Topisirovic I, Guzman ML, McConnell MJ, et al. Aberrant eukaryotic translation initiation factor 4E-dependent mRNA transport impedes hematopoietic differentiation and contributes to leukemogenesis. Mol Cell Biol. 2003;23(24):8992-9002

32. Shahbazian D, Parsyan A, Petroulakis E, et al. Control of cell survival and proliferation by mammalian eukaryotic initiation factor 4B. Mol Cell Biol. 2010;30(6):1478-1485

33. Assouline S, Culjkovic B, Cocolakis E, et al Molecular targeting of the oncogene eIF4E in acute myeloid leukemia (AML): a proof-ofprinciple clinical trial with ribavirin. Blood. 2009;114(2):257-260.

34. Hess J, Angel P, Schorpp-Kistner M. AP-1 subunits: quarrel and harmony among siblings. J Cell Sci. 2004:117(Pt 25):5965-5973

35. Liebermann DA, Gregory B, Hoffman B. AP1 (Fos/Jun) transcription factors in hematopoietic differentiation and apoptosis. Int J Oncol. 1998;12(3):685-700.

36. Passegue E, Wagner EF, Weissman IL. JunB deficiency leads to a myeloproliferative disorder arising from hematopoietic stem cells. Cell. 2004;119(3):431-443.

37. Brach MA, Herrmann F, Kufe DW. Activation of the AP-1 transcription factor by arabinofuranosylcytosine in myeloid leukemia cells. Blood. 1992;79(3):728-734

38. Shafarenko M, Amanullah A, Gregory B, Liebermann DA, Hoffman B. Fos modulates myeloid cell survival and differentiation and partially abrogates the c-Myc block in terminal myeloid differentiation. Blood. 2004;103 (11):4259-4267. 